\title{
Analysis of Cryptocurrency Risks and Methods of their Mitigation in Contemporary Market Conditions
}

\author{
Elena Nadyrova \\ Master student, Faculty of International Finance, Financial University, Moscow, Russia \\ ddasamm@mail.ru
}

\begin{abstract}
In the course of the research, we identified seven risk groups, analyzed their influence, and formulated possible measures of the risk mitigation. For initial coin offerings projects, we formulated a special riskassessment scoring system based on a 100-point scale. Investment risks (volatility) were one of the main issues. The only effective option of risk-management here is risk aversion - the refusal of any interaction with the cryptocurrency market. On the other hand, traditional risk management method of diversification has proved its worth and viability on empirical studies of portfolio investments. The portfolio should not be mostly "crypto" but rather it should also consist of traditional assets. It is necessary to consider the opportunity to quit the cryptocurrency market for a short period of time, to prevent the harmful consequences of dramatic price shifts.

Keywords: cryptocurrency; cryptocurrency market; Bitcoin; risk-management; diversification; investment portfolio JEL Classification: G02, G11, G29
\end{abstract}

$\mathrm{T}$ he Blockchain technology and cryptocurrency market can truly be considered revolutionary and innovative. Generally, all the ideas incorporated in the system were known earlier but only in 2009, the Bitcoin authors managed to put all together and make them work.

In the pursuit of revolutionism, many concentrate on the advantages and often forget to assess the real state of the system. So, what are the risks if cryptocurrency is used for legitimate purposes?

Considered as an asset or a currency, risks associated with both classes may be typical for the cryptocurrency. However, specific principles sometimes make the probability of the problems higher and consequences - more unpleasant. In addition, they may define a number of risks that are unique for cryptocurrencies as a separate class.

Since its existence, the cryptosystem has demonstrated security and reliability. But various third-party online services that operate within this system - exchanges, wallets, etc.- can become the target of hacker attacks. Security risks of using the system are the following: substitution of payment details and fishing, loss or theft of private keys, platform hacking, closing exchanges, etc.

Operating without licenses or being hacked, any exchange may close overnight. To reduce the potential risk of losing funds one may store cryptocurrencies in the wallet. But on the other hand, money may be stolen by malware or disappear because of hard disk failure. Therefore, the most advanced users record a copy of the secret key on an ordinary piece of paper and have hardware USB-wallets. Notably, the hackers' community is also developing. It uses innovative technologies and sophisticated hacking tools as Blockchain does. That is why there are no methods or mechanisms that would completely exclude security risks. But advanced users can take the following measures to limit and mitigate them: to check and recheck addresses and all the transaction information, not to follow suspicious links; to use the hardware wallets for cryptocurrency; to use high-quality anti-virus protection, etc. 
Table 1

Output data

\begin{tabular}{lcc}
\hline \multicolumn{1}{c}{ Characteristics } & Symbol & Value \\
\hline Hashing power & $\mathrm{h}$ & $14 \mathrm{TH} / \mathrm{s}$ \\
Power consumption & $\mathrm{p}$ & $1475 \mathrm{~W}$ \\
Cost of the miner & $\mathrm{C}$ & $2400 \mathrm{USD}$ \\
Exchange rate (Bitstamp) & $\mathrm{ER}$ & 7720 USD $/$ BTC \\
Block reward & $\mathrm{R}$ & $12.5 \mathrm{BTC}$ for a block \\
Difficulty & $\mathrm{D}$ & $3.51 \mathrm{e}+12$ \\
Time accounted & $\mathrm{t}$ & 1 day $=86400 \mathrm{~s}$ \\
Electricity cost per kWh (USA) & $\mathrm{E}$ & $0.12 \mathrm{USD}$ \\
\hline
\end{tabular}

Source: https://www.bitstamp.net/, https://www.eia.gov/electricity/, https://shop.bitmain.com.

Table 2

Sensitivity analysis of daily net income and payback period

\begin{tabular}{cccccc}
\hline $\begin{array}{c}\text { Change in } \\
\text { cost }\end{array}$ & $\begin{array}{c}\text { Electricity } \\
\text { cost }\end{array}$ & $\begin{array}{c}\text { Daily net income } \\
\text { (Incomei-OPEX) }\end{array}$ & $\begin{array}{c}\text { Change in } \\
\text { net income }\end{array}$ & $\begin{array}{c}\text { Payback period } \\
\text { (years) }\end{array}$ & $\begin{array}{c}\text { Change in a } \\
\text { payback period }\end{array}$ \\
\hline$-50 \%$ & 0.06 & 5.62 & $61 \%$ & $1 \mathrm{y} 3 \mathrm{~m}$ & $-38 \%$ \\
$-40 \%$ & 0.072 & 5.19 & $49 \%$ & $1 \mathrm{y} 4 \mathrm{~m}$ & $-33 \%$ \\
$-30 \%$ & 0.084 & 4.77 & $36 \%$ & $1 \mathrm{y} 5 \mathrm{~m}$ & $-27 \%$ \\
$-20 \%$ & 0.096 & 4.34 & $24 \%$ & $1 \mathrm{y} 7 \mathrm{~m}$ & $-20 \%$ \\
$-10 \%$ & 0.108 & 3.92 & $12 \%$ & $1 \mathrm{y} 9 \mathrm{~m}$ & $-11 \%$ \\
$0 \%$ & 0.12 & 3.49 & $0.0 \%$ & $1 \mathrm{y} 11 \mathrm{~m}$ & $0 \%$ \\
$10 \%$ & 0.132 & 3.07 & $-12 \%$ & $2 \mathrm{y} 2 \mathrm{~m}$ & $14 \%$ \\
$20 \%$ & 0.144 & 2.64 & $-24 \%$ & $2 \mathrm{y} 6 \mathrm{~m}$ & $32 \%$ \\
$30 \%$ & 0.156 & 2.22 & $-36 \%$ & $3 \mathrm{y}$ & $57 \%$ \\
$40 \%$ & 0.168 & 1.79 & $-49 \%$ & $3 \mathrm{y} 8 \mathrm{~m}$ & $95 \%$ \\
$50 \%$ & 0.18 & 1.37 & $-61 \%$ & $4 \mathrm{y} 10 \mathrm{~m}$ & $155 \%$ \\
\hline
\end{tabular}

Source: author's calculations.

Technical risks are not fully disclosed within this work since it is a separate topic for the study but some risks associated with mining equipment should be mentioned.

On average, mining consumes 20,000 GWh per year or $0.1 \%$ of the world electricity production. This is almost equal to the energy consumption of a country like Ireland. Therefore, the issue of electricity prices is very acute for cryptocurrency
(Cocco et al., 2016). Let us simulate the mining process with the following data (Table 1).

Considering mining is a classical project where you invest capital and expect to have some income during the life of the asset (n), and omitting the time value of money concept, depreciation and power supply unit (150-200 USD), the mining profit formulas are the following: 


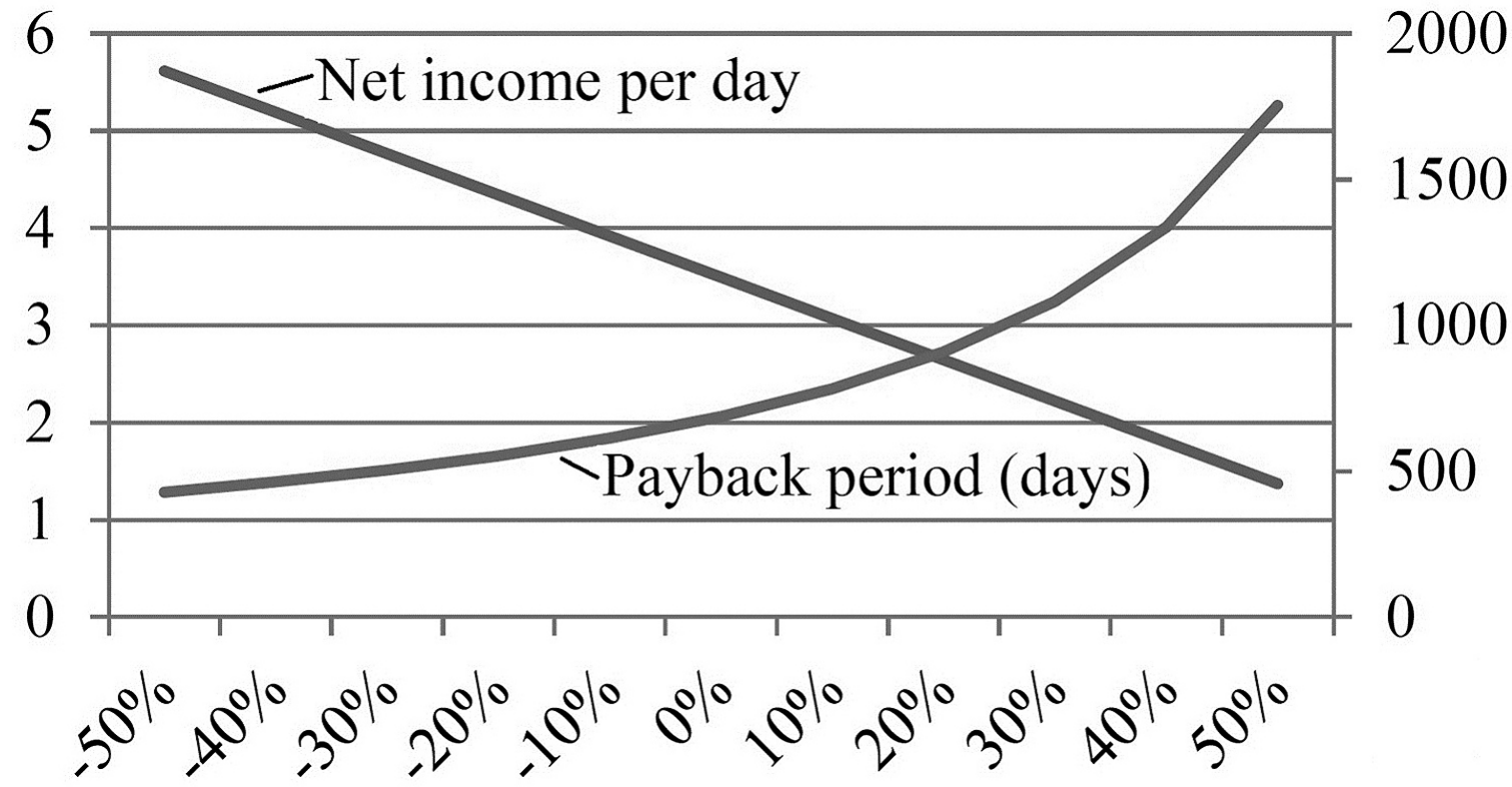

Figure 1. Sensitivity analysis.

Source: the author's calculations.

$$
N P V=-C A P E X-\sum_{i=1}^{n} \operatorname{OPEX}_{i}+\sum_{i=1}^{n} \text { Income }_{i},
$$

where: $C A P E X($ cost of the miner $)=c$,

$$
\begin{aligned}
& \text { OPEX }(\text { daily electricity cost })=24 * \frac{p}{1000} * \mathrm{ER}, \\
& \text { Income }(\text { daily mining income })=\frac{h^{*} t^{*} R}{2^{32} * D} * E R . \\
& \text { Payback Period in days }=\frac{C A P E X}{\text { Income }_{i}-\text { OPEX }}
\end{aligned}
$$

In Table 2 is the result of sensitivity analysis in case of electricity cost fluctuations. Interestingly, the initial electricity value prices were based on US experience. If Russia or China was taken for example where electricity cost is much smaller -9.1 cents $/ \mathrm{kWh}$, mining procedure would be more profitable.

Such result as a 2-year payback period implies that all the factors, especially bitcoin exchange rate, would be stable and remain the same that is extremely unlikely in the rapidly changing world of cryptocurrency (Hassani, 2016). According to the Goldman Sachs valuations, reaching the price of $5,900 \$$ makes mining almost unprofitable even in comparison with bank deposits.
Figure 1 provides sensitivity analysis graphs of electricity cost dependent on the change of net income per day and payback period in days.

All in all, utility prices raised by $10 \%$ will lead to a $12 \%$ decrease in net income per day and $14 \%$ increase in overall payback period. It should be taken into account that the mining difficulty changes over time. With expanding equipment processing power, the difficulty also increases but the income of each individual miner falls proportionally. Assuming $10 \%$ rise in electricity cost and 5\% difficulty growth rate every 15 days, all other things being equal, mining will cease to be profitable in 5 months.

If it goes to the industrial level, the situation will dramatically change. Unfortunately, this is the only way how to mitigate the risk connected with electricity costs while mining cryptocurrency and it requires significant funds. Even if an operator changes a country to the one with lower tariffs, increasing mining difficulty will still make it unprofitable after a while. In this sphere, the main thing is to keep up with technical trends and technology.

Risks associated with ICO. Raising money through ICO picks up speed and exceeds the amount of venture investment in blockchain projects. In 2016 about $\$ 600$ million of venture capital (VC) was invested in start-ups at cryptocurrency markets against one-third of this amount $-\$ 256$ million - totalled by ini- 


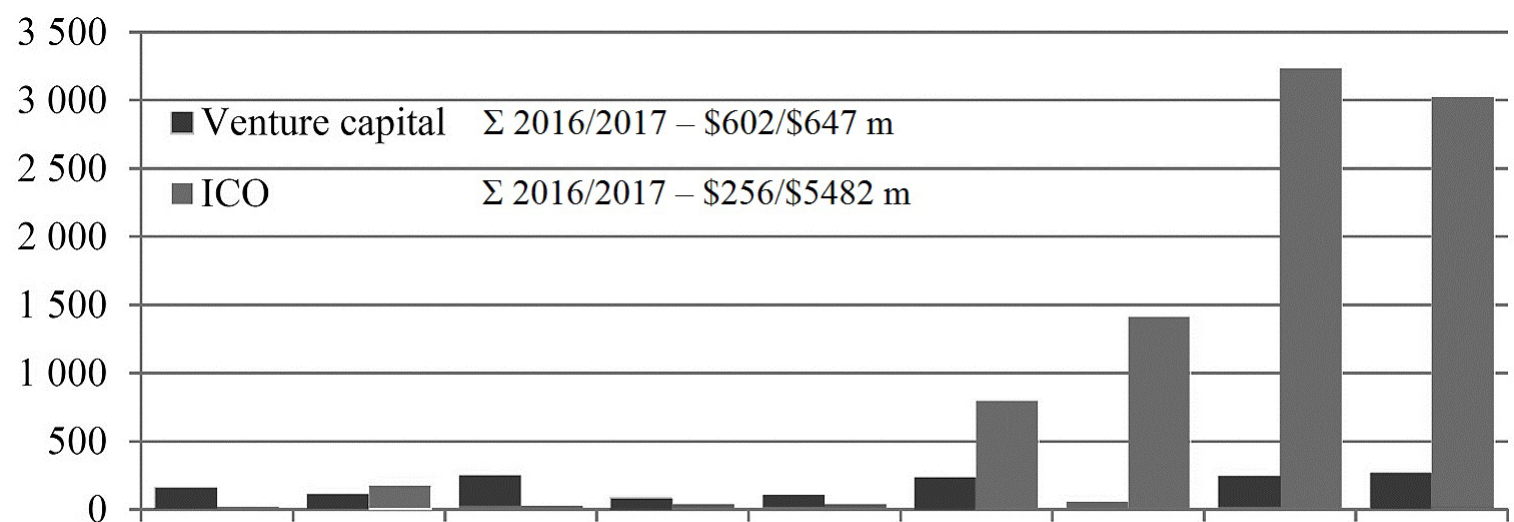

Q1 2016 Q2 2016 Q3 2016 Q4 2016 Q1 2017 Q2 2017 Q3 2017 Q4 2017 Jan-Feb2018

Figure 2. Investment in Blockchain by a quarter of 2016-2018, \$ million.

Source: https://www.coindesk.com.
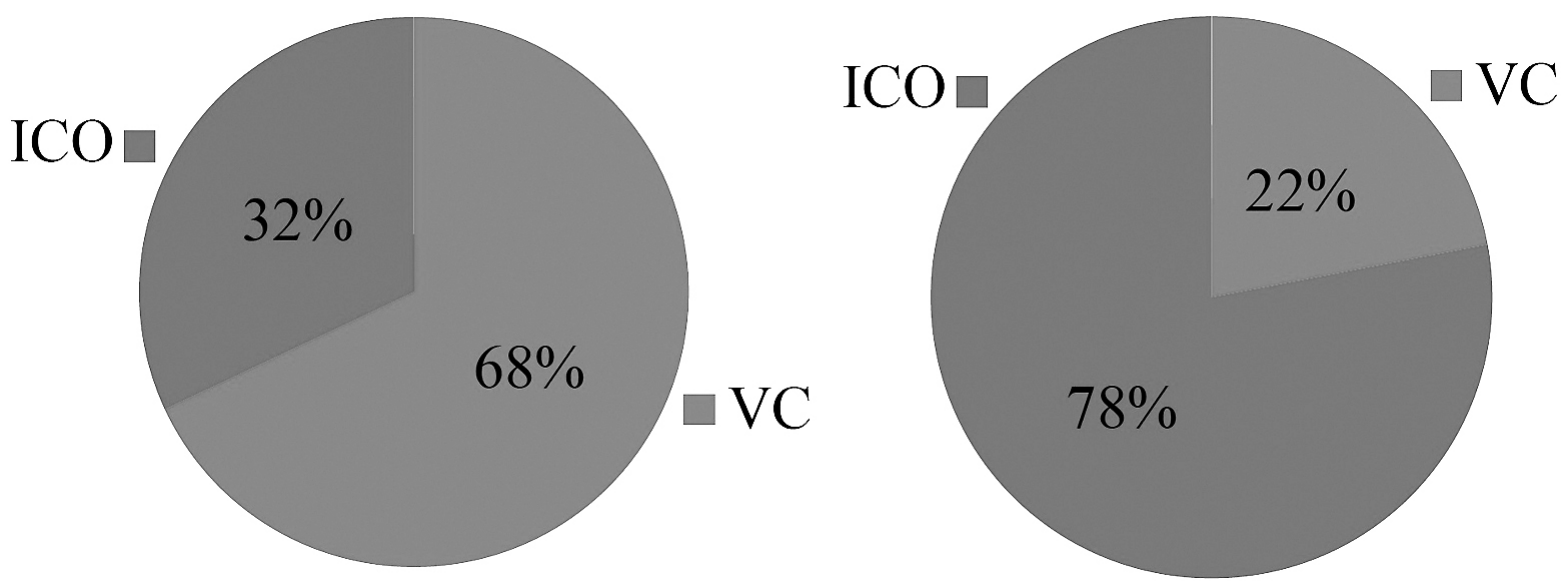

Figure 3. Blockchain deal (left) and dollar (right) volume by funding, 2017-February 2018.

Source: https://www.crunchbase.com.

tial coin offers (Figure 2). In 2017 an opposite trend was observed: entrepreneurs raised about $\$ 5.5$ billion leaving venture capital funding far behind - \$ 647 million. The largest deal was the first regulated ICO - Filecoin - that set a new record for the cryptocurrency industry and collected \$ 257 million. Another one - Tezos raised about $\$ 230$ million.

The number of ICOs from January 2016 to February 2017 is smaller $-32 \%$ and $68 \%$ for VC respectively (Figure 3). But the dollar volume raised through ICO exceeds the greatest expectations in comparison to venture - by a factor of 4 .

The low entry barriers attract investors. The price of the token can start from a few cents. In case of successful projects investing would be a big deal. According to Table 3, the highest yields relate to tokens of NXT (an increase of 1 million per cent since the ICO), IOTA (334 thousand per cent) and Neo (214 thousand per cent) projects.

But at ICO it is quite probable both to earn and lose money. A potential investor can make a comprehensive examination of the project but the success of the ICO will depend on a number of factors beyond the control of the project creators. There is a high probability that the ICO will go wrong as it was not expected. Last year, only $41 \%$ of the projects really succeeded (Token Sales \& ICOs List). Although there is no much news about them, investors are not losing optimism and continue to invest.

In some countries, ICOs are generally prohibited considered fraudulent (China). So, there is a risk of change in regulation (legal and regulatory 
risks) that can lead, for example, to inability to monetize tokens. In the end, ICO initiators can simply disappear with money because it is not so easy to track down and de-anonymize the payee. Moreover, during the ICO, hackers can get access to the project site and change the address at the very moment of its opening (security risks).

The problem is that the cryptocurrency market is not regulated, there are no risk assessment mechanisms, and the return on investment is not guaranteed. The project is assessed by the public excitement around ICO that leads to extreme volatility in the subsequent trading.

It is important to note that most ICOs are realized when the project is at its "idea" (84\%) or "prototype" (11\% of projects 2017 ) stages. Therefore, there is a low probability to have any historical data and financial indicators in general to apply typical valuation frameworks and quantitative analysis. The only way to evaluate projects and their risks is to turn to the experience of venture capitalists and apply fundamental and qualitative analysis. Some help can be provided by rating agencies involved in the ICO analysis: ICO Rating, ICO Bench, etc.

For ICO projects the special scoring system was formulated. It is based on the following criteria those are assessed on a 100-point scale:

Team -30 points. Preferably, a project should be founded by entrepreneurs who already have successful work experience and good reputation. Presence of credible advisors and participation of financial institutions are also advantages. It is necessary to try to analyse the environment inside the project, the background of each participant, their location (whether the team is able to cooperate with each other quickly) and age. The team should be open and highly engaged in communication with potential investors to be able to clear doubts and questions about oncoming ICO.

Overall concept -20 points. The idea of a project should be simple and realistic. The team must set big but achievable goals, have a clear understanding of how the project will develop after raising investment over the time (development roadmap) and not overflow the whitepaper with marketing terms. Another important aspect is the scalability of an idea. The project audience should not be limited by regional bounds
Table 3

Changes of tokens $\mathrm{ROI}$ since ICO

\begin{tabular}{lc}
\hline \multicolumn{1}{c}{ Token } & Value \\
\hline NXT & $+1,019,715 \%$ \\
IOTA & $+334,073 \%$ \\
Neo & $+214,059 \%$ \\
Ethereum & $+168,728 \%$ \\
Stratis & $+67,056 \%$ \\
\hline
\end{tabular}

Source: https://icostats.com.

or very narrow activities or interests to support substantial growth.

Token analysis -40 points. At the ICO stage, it is impossible to calculate liquidity but it can be predicted by analysing the following factors:

Inflationary/deflationary economic model of the token - whether the supply is limited. For future growth deflationary model, like bitcoin, represents higher interest.

Sales policy: capped/uncapped, (crypto-) currency of investment, discounts for earlier investors, extra issue/withdrawal.

Bonuses: Large bonuses negatively affect investments.

Use in the ecosystem: to what extent it is a clone of existing cryptocurrencies and what distinctive features give value. The higher its need the greater is the demand.

Token capitalization, distribution through ICO/pre-ICO and its share allocated to the issuer: Probably, one-third of the total is a good indicator. It means that the founders have an incentive to develop and maintain liquidity.

Platform choice and legal barriers: The most common option is to use Ethereum. If an idea behind the project is more complicated, another platform can be used. It is crucial to analyse the code of the smart contract, platform code and statistics on the subject of errors. An additional measure may be a code audit.

Social popularity -10 points. The analysis is based on activity in social networks, messengers, forums, and mass-media. If the activity is low, the even good project may fail.

Interpretation of the data obtained is carried out with the use of expert judgement. Providing 
the highest evaluation results of most factors, some group may lag behind. Then it becomes important to give this group special attention and, perhaps, to abandon the project in view of the increased risks. The indicators obtained in the analysis process will help assess risks and better understand the economics of the ICO project. The best way is to look for quality projects with strong teams. They are the ones most likely to be successful in the long run.

Legal and regulatory risks are related to actions of state authorities that seek to establish legal status for cryptocurrencies and rules for its use. Since Bitcoin is a completely decentralized peer-to-peer system that does not have a single control centre, states do not have a direct mechanism to influence its performance. But the state can do the following: send negative signals to the financial market; regulate the interconnected sphere of fiat money (Kozina, 2017); introduce criminal liability for cryptooperations, etc. It can go the other way - to make a competitor and create its own cryptocurrency. Likelihood and impacts of these risks depend on the economic market and state policies in a country. The key to overcoming legal challenges may be open communication with law enforcement and regulators in order to reach a common agreement and elaborate the universal approach to the legal status of cryptocurrencies and tax issues.

Social risks or risks of acceptance come from the public. It is the risk of trust - how far the public trust in a new phenomenon will go. In comparison to fiat money, Bitcoin is voluntary. If individuals and institutions decide no longer to accept it, this cryptocurrency will become useless and worthless. The very idea of cryptocurrency will fail. To a large extent, it depends on activities of mass media.

Obviously, the acceptance of cryptocurrency by population will be more common in countries where confidence in local currency falls, inflation is high and the government does not cope well with financial crises (crisis of trust). For example, it is already happening in Venezuela that was the first in the world to launch the national currency El Petro backed by oil.

Thus, social risks are inevitable and may have positive impacts as global recognition and adoption of Bitcoin grow. They are also in-

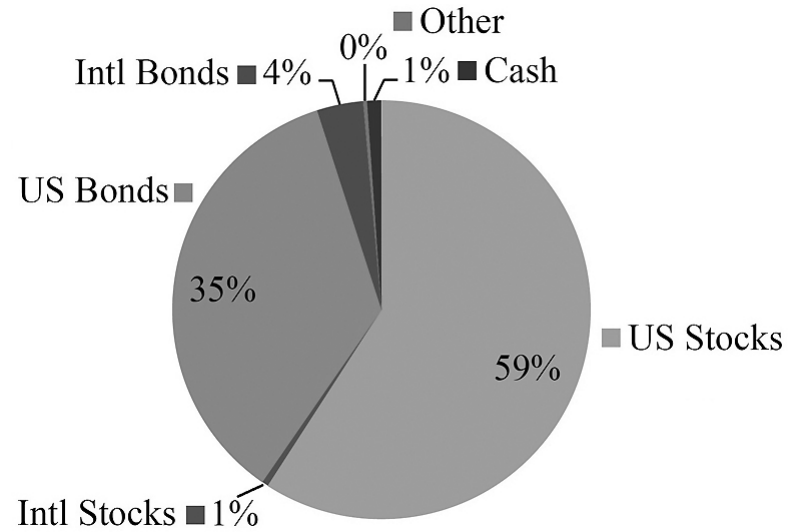

Figure 4. The asset allocation of indices.

Source: https://investor.vanguard.com.

terconnected with technological and especially legal challenges. Any technological problem will increase social risks too, as well as various prohibitions and restrictions in the cryptocurrency market introduced by the legislative authorities.

Investment risks are one of the key issues because they are connected with volatility. It acts as a keystone of the bitcoin investment potential and a serious risk. In certain periods of time, the price of cryptocurrency has an exponential growth and after it blows up like a bubble. Because cryptocurrency has neither an intrinsic value nor is capable of being valued according to fundamental analysis, the institutional investors are largely staying away. Crypto-currencies instead rely on individual investors worldwide. The downside is that individual investors are rarely buy-and-hold investors or have a longterm investment horizon, whereas institutional investors take the long view of their assets and may be content to hold particular assets for years before they pan out. The lack of institutional investors, with their buy-and-hold views, is one of the biggest reasons for the extreme volatility of cryptocurrencies.

Now, lots of ways of risk mitigation exist: starting with insurance, otherwise called hedging, following the rule to invest not in altcoins but in the ideas embodied, and ending with the simple advice "not to put all the eggs in one basket" (Kanuri et al., 2018). Anyway, they cannot guarantee complete elimination of risks - unless not to participate in transactions at this market at all (risk aversion). But there is still a risk of losing fiat capital as a result of inflationary processes and economic crises that, 


\begin{tabular}{|c|c|c|c|}
\hline \multirow{2}{*}{ Metric } & Provided Portfolio & $\begin{array}{l}\text { Max Return at } 4 \% \\
\text { Volatility }\end{array}$ & $\begin{array}{c}\text { Min Volatility at } 20 \% \\
\text { Return }\end{array}$ \\
\hline & 1 & 2 & 3 \\
\hline VTSMX & $60 \%$ & $32.59 \%$ & $65.05 \%$ \\
\hline VBMFX & $40 \%$ & $66.35 \%$ & $31.4 \%$ \\
\hline BTC & $0 \%$ & $1.06 \%$ & $3.55 \%$ \\
\hline Start Balance & $\$ 10,000$ & $\$ 10,000$ & $\$ 10,000$ \\
\hline End Balance & $\$ 11,270$ & $\$ 11,090$ & $\$ 12,526$ \\
\hline End Balance (inflation adjusted) & $\$ 10,903$ & $\$ 10,729$ & $\$ 12,118$ \\
\hline CAGR & $10.03 \%$ & $8.63 \%$ & $19.74 \%$ \\
\hline CAGR (inflation adjusted) & $7.16 \%$ & $5.79 \%$ & $16.61 \%$ \\
\hline Expected Return & $10.14 \%$ & $8.68 \%$ & $20.00 \%$ \\
\hline Stdev & $4.40 \%$ & $3.23 \%$ & $6.63 \%$ \\
\hline Sharpe Ratio & 1.92 & 2.21 & 2.54 \\
\hline US Stock Market Correlation & 0.98 & 0.73 & 0.75 \\
\hline Mean Return (annualized) & $10.14 \%$ & $8.68 \%$ & $20.00 \%$ \\
\hline Compound Return (annualized) & $10.03 \%$ & $8.63 \%$ & $19.74 \%$ \\
\hline Volatility (annualized) & $4.56 \%$ & $3.35 \%$ & $6.87 \%$ \\
\hline Market Correlation & 0.98 & 0.73 & 0.75 \\
\hline Beta & 0.59 & 0.32 & 0.68 \\
\hline Historical Value-at-Risk (5\%) & $-2.64 \%$ & $-1.83 \%$ & $-2.54 \%$ \\
\hline Positive Periods & 13 / 15 (87\%) & 12 / 15 (80\%) & 12 / 15 (80\%) \\
\hline Gain/Loss Ratio & 0.67 & 1.25 & 1.33 \\
\hline
\end{tabular}

Source: author's calculations.

according to Karl Marx, inevitably occur under capitalism.

The optimal way to distribute risks is to diversify and create a well-balanced investment portfolio (Anyfantaki et al., 2018). In order to predict the value of the cryptocurrency and its prospects, it is necessary to consider the following factors: market share, the practical value of the altcoin, the volume of transactions, liquidity, technology development and market news. Cryptocurrency indices help to understand general dynamics and investors' attitude.

The difficulty is that investing within the same crypto-sphere does not always hedge against volatility risk. The bulk of altcoins follows BTC, and therefore such investments can- not solve the issue. In order to, at least, partially secure savings, crypto-investments should be combined with time-proven traditional funding placed in real estate, precious metals, the stock of developing companies, etc.

To identify the optimal rebalancing method, two types were studied: timing-rebalancing (after a certain period of time) and percentbalancing (in the case when the deviation is specified within the portfolio). Both work better than the portfolio "un-rebalanced" at all. There is also an opinion that in the cryptomarket rebalances must be conducted every day because of high volatility. The researches performed show that frequent rebalancing is useless taking into account no commission. 
Table 5

Portfolio Risk Decomposition

\begin{tabular}{cccc}
\hline Ticker & Provided Portfolio, \% & $\begin{array}{c}\text { Maximum Return at 4\% } \\
\text { Volatility, \% }\end{array}$ & $\begin{array}{c}\text { Min Volatility at 20\% } \\
\text { Return, \% }\end{array}$ \\
\hline VTSMX & 97.93 & 53.76 & 53.82 \\
VBMFX & 2.07 & 23.01 & 3.19 \\
BTC & & 23.23 & 42.99 \\
\hline
\end{tabular}

Source: author's calculations.

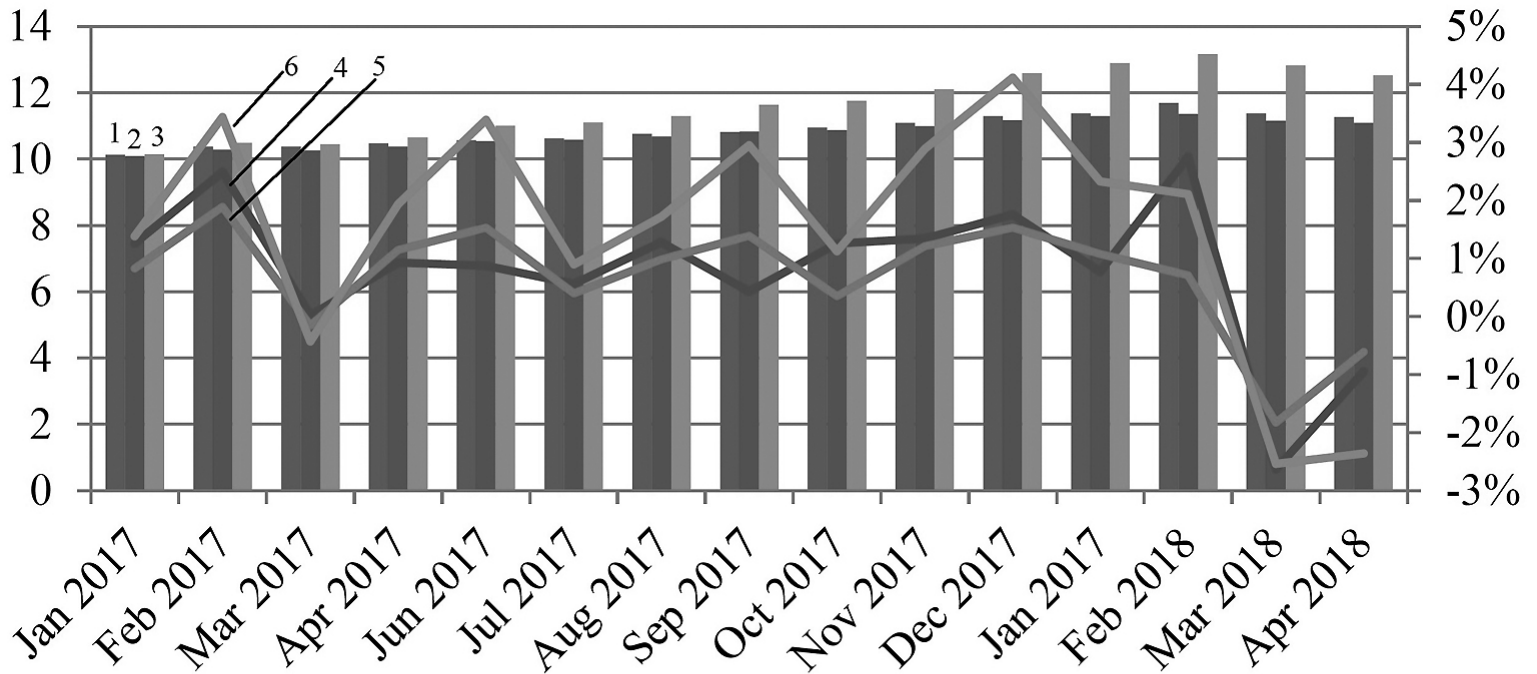
1 Provided Portfolio Balance, th.\$
2 Maximum Return at 4\% Volatility Balance, th.\$
3 Minimum Volatility at 20\% Return Balance, th.\$
4 Provided Portfolio Return (sec. axis)
5 Maximum Return at 4\% Volatility Return (sec. axis)
$6 \simeq$ Minimum Volatility at 20\% Return Return (sec. axis)

Figure 5. Portfolios growth.

Source: author's calculations.

With the fee, frequent rebalancing will worsen portfolio even more.

Let us focus on timing-rebalancing with an optimal period of 31 days, that is, change in portfolio structure every month. As the market matures (decrease in the standard deviation of daily return), it is necessary extending the rebalancing period. At the fiat markets, it may be enough to rebalance once in six months/year.

To test the efficiency of diversification method, the investment portfolio is created. Traditional asset allocation - $60 \%$ shares and $40 \%$ bonds - is considered. A simple strategy presented in Figure 4 will be to use 60\% Vanguard
Total Stock Mkt Idx Inv (VTSMX, large blend category) and 40\% Vanguard Total Bond Market Index Inv (VBMFX, intermediate-term bond).

The expected return of this portfolio is about $10 \%$, annualized volatility $-4.6 \%$. Start year 2017, the month-to-month time period from January 2017 to March 2018, initial balance 10,000 USD.

Having chosen this strategy as a basis, the aim is to form a better portfolio with the help of Bitcoin. The original allocation will be modified with the new asset class. Optimization goals - to maximize return subject to $4 \%$ annual volatility and to minimize volatility subject to $20 \%$ annual return. 
Table 6

Correlation of assets

\begin{tabular}{ccccccccc}
\hline Ticker & VTSMX & VBMFX & BTC & NFLX & BA & PYPL & AMZN & MSFT \\
\hline VTSMX & - & -0.27 & 0.13 & 0.51 & 0.55 & 0.52 & 0.48 & 0.75 \\
VBMFX & -0.27 & - & -0.02 & -0.07 & -0.18 & -0.03 & -0.07 & -0.09 \\
BTC & 0.13 & -0.02 & - & 0.18 & 0.05 & 0.18 & 0.04 & 0.11 \\
NFLX & 0.51 & -0.07 & 0.18 & - & 0.26 & 0.40 & 0.52 & 0.50 \\
BA & 0.55 & -0.18 & 0.05 & 0.26 & - & 0.32 & 0.25 & 0.40 \\
PYPL & 0.52 & -0.03 & 0.18 & 0.40 & 0.32 & - & 0.43 & 0.52 \\
AMZN & 0.48 & -0.07 & 0.04 & 0.52 & 0.25 & 0.43 & - & 0.62 \\
MSFT & 0.75 & -0.09 & 0.11 & 0.50 & 0.40 & 0.52 & 0.62 & - \\
\hline
\end{tabular}

Source: author's calculations.

Table 7

Portfolio analysis

\begin{tabular}{|c|c|c|}
\hline Metric & Provided Portfolio & Min Volatility at same return \\
\hline NFLX & $12.65 \%$ & $1.16 \%$ \\
\hline BA & $28.21 \%$ & $26.31 \%$ \\
\hline PYPL & $27.58 \%$ & $0 \%$ \\
\hline MSFT & $31.56 \%$ & $66.49 \%$ \\
\hline BTC & $0 \%$ & $6.04 \%$ \\
\hline Start Balance & $\$ 10,000$ & $\$ 10,000$ \\
\hline End Balance & $\$ 19,212$ & $\$ 19,312$ \\
\hline End Balance (inflation adjusted) & $\$ 18,587$ & $\$ 18,684$ \\
\hline CAGR & $68.60 \%$ & $69.30 \%$ \\
\hline CAGR (inflation adjusted) & $64.20 \%$ & $64.88 \%$ \\
\hline Expected Return & $71.29 \%$ & $71.29 \%$ \\
\hline Stdev & $18.90 \%$ & $15.83 \%$ \\
\hline Sharpe Ratio & 2.77 & 3.3 \\
\hline US Stock Market Correlation & 0.73 & 0.65 \\
\hline Mean Return (annualized) & $71.29 \%$ & $71.29 \%$ \\
\hline Compound Return (annualized) & $68.60 \%$ & $69.30 \%$ \\
\hline Volatility (annualized) & $19.57 \%$ & $16.38 \%$ \\
\hline Market Correlation & 0.73 & 0.65 \\
\hline Beta & 1.88 & 1.4 \\
\hline Historical Value-at-Risk (5\%) & $-4.57 \%$ & $-6.40 \%$ \\
\hline Positive Periods & 13 / 15 (86.67\%) & 14 / 15 (93.33\%) \\
\hline Gain/Loss Ratio & 2.28 & 0.84 \\
\hline
\end{tabular}

Source: author's calculations. 
Table 8

Asset analysis

\begin{tabular}{cccccc}
\hline Ticker & Expected Return & $\begin{array}{c}\text { Standard } \\
\text { Deviation }\end{array}$ & Sharpe Ratio* & Min. Weight & Max. Weight \\
\hline NFLX & $113.83 \%$ & $41.51 \%$ & 2.721 & $0 \%$ & $100 \%$ \\
BA & $92.29 \%$ & $27.75 \%$ & 3.294 & $0 \%$ & $100 \%$ \\
PYPL & $72.32 \%$ & $22.32 \%$ & 3.200 & $0 \%$ & $100 \%$ \\
MSFT & $40.18 \%$ & $14.36 \%$ & 2.735 & $0 \%$ & $100 \%$ \\
BTC & $696.48 \%$ & $118.13 \%$ & 5.888 & $0 \%$ & $100 \%$ \\
\hline
\end{tabular}

* Ex-ante Sharpe Ratio calculated using historical 1-month Treasury bill returns as the risk-free rate $(0.90 \%$ annualized).

Source: author's calculations.

Table 9

Portfolio Risk Decomposition

\begin{tabular}{ccc}
\hline Ticker & Name & $\begin{array}{c}\text { Minimum Volatility at 71.29\% } \\
\text { Return }\end{array}$ \\
\hline NFLX & Netflix, Inc. & $1.52 \%$ \\
BA & Boeing Company & $30.54 \%$ \\
MSFT & Microsoft Corporation & $48.20 \%$ \\
BTC & Bitcoin Market Price & $19.73 \%$ \\
\hline
\end{tabular}

Source: author's calculations.

It turned out that in order to reduce the portfolio volatility to $4 \%$ it is enough to have $1 \%$ Bitcoin. The result is shown in Table 4. Beta and market correlation was calculated against the US stock market. Value-at-risk metrics are based on monthly returns.

By the way, adding $4 \%$ bitcoins increases portfolio return by 2 times with minimum annualized volatility of $7 \%$. In Table 5 , risk factor analysis by the asset is given.

The general trend is the drawdown of all portfolios in 2018 due to a decrease in the return on assets:

Vanguard Total Stock Mkt Idx Inv - about 4\% in February and 2\% March;

Vanguard Total Bond Market Index Inv - 1\% in January and February each;

Bitcoin Market Price USD - 28\% in January and $36 \%$ in March.

Having the same asset allocation "unrebalanced", an investor could get accumulated funds of $\$ 11,294$ (4.81\% volatility and $10.34 \%$ return), $\$ 11,454$ (8.13\% volatility and $11.81 \%$ return) and $\$ 13,611$ (20.67\% volatility and $30.47 \%$ return) for respective Portfolios in the end (Figure 5).

Considering long-term investments in the same assets since 2009 (appearance of Bitcoin), the original " $60 / 40$ " portfolio without BTC will have $6.84 \%$ volatility, $10.34 \%$ return and \$20,733 final balance. Reducing the volatility to $6 \%$ by adding $1.5 \%$ BTC, we obtain $\$ 22,790$ in March 2018 (11.67\% expected return). No rebalancing will lead to the final result of $\$ 19,182$ for Portfolio 1 and the phenomenal sum of \$3,460,733 for Portfolio 2! But volatility will also be enormous - $169 \%$.

Let us compose aggressive growth stock portfolio maximizing diversification ratio. Leaders by stock growth over the past 12 months were Netflix (NFLX), The Boeing Company (BA), PayPal Holdings, Inc. (PYPL), Amazon.com, Inc. (AMZN) and Microsoft Corporation (MSFT). Ac- 


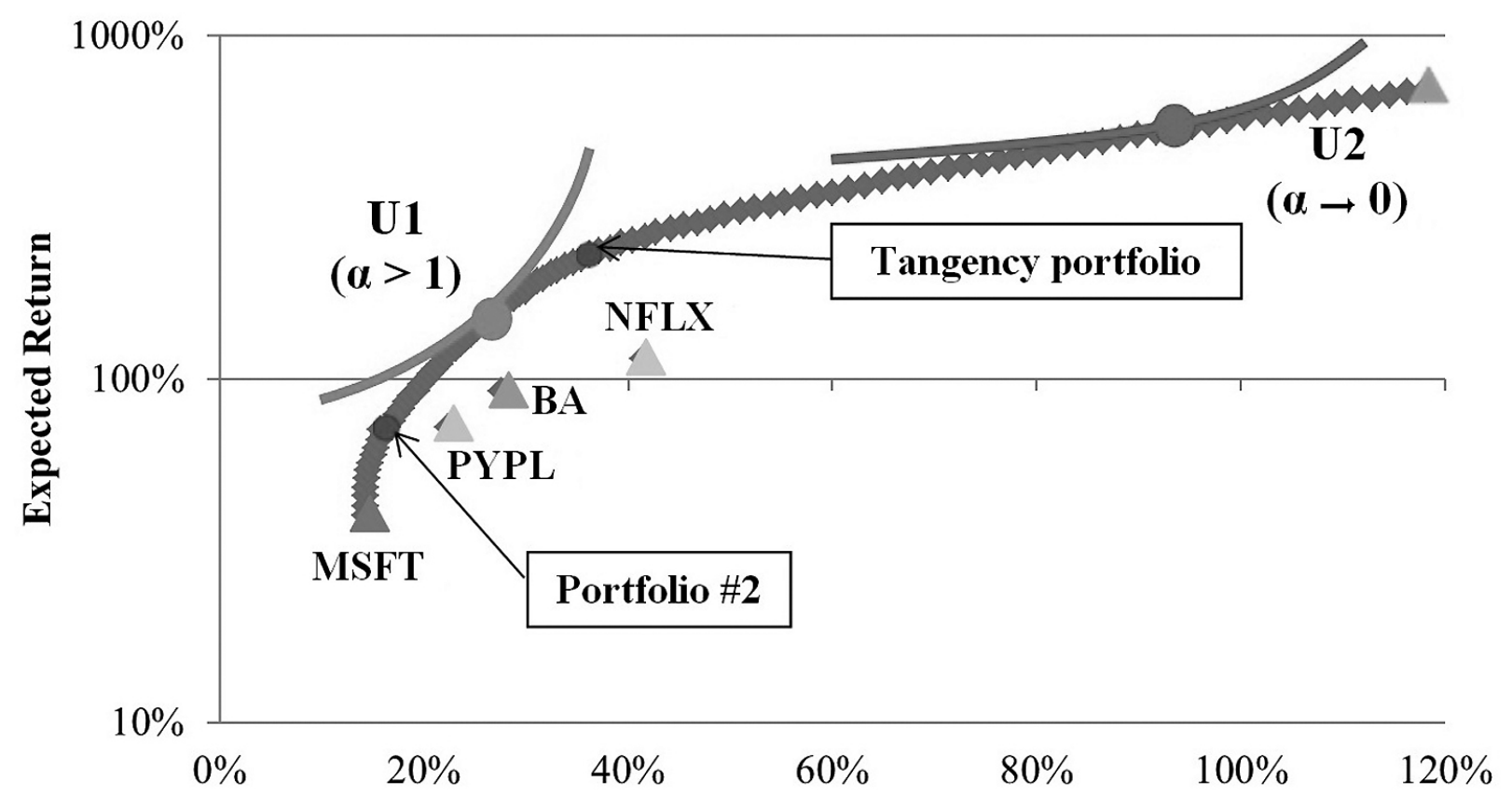

\section{Standard Deviation}

Figure 6. Efficient frontier for Portfolio No. 2.

Source: author's calculations.

Table 10

Portfolio analysis

\begin{tabular}{lcc}
\hline & Aggressive crypto-portfolio No. 1 & Diversified portfolio No. 2 \\
\hline Asset & BTC - 50\%, ETC - 30\%, & Cryptocurrencies - 30\%: BTC - 10\%, ETC - 10\%, XRP - 10\% \\
allocation & XRP - 20\% & Stock: Apple - 10\%, NFLX - 20\% \\
& & Commodities \& energy: Brent - 20\%, Gold - 20\% \\
Start Balance & $10,000.00$ & $10,000.00$ \\
End Balance & $5,299.57$ & $10,018.85$ \\
Earnings/ & $-4,700.43$ & 18.8 \\
losses & & \\
Exp. return & $-17.6 \%$ & $12.5 \%$ \\
St. deviation & $75.5 \%$ & $4.3 \%$ \\
Dispersion & $57 \%$ & 0.18 \\
\hline
\end{tabular}

Source: author's calculations.

cording to main diversification rule, the stock of companies within different industries should be included. At table 6, it is a correlation of the above-mentioned assets for time period 01/01/2017-31/03/2018 based on daily returns. No high correlation is observed.

For the second portfolio, the goal is to reduce volatility by adding BTC and save return at the same time. Cryptocurrency successfully deals with this task $-3 \%$ BTC volume decreases the volatility of the entire portfolio by $3 \%$ but with the elimination of PayPal stocks (Table 7).
The possible range of expected annual portfolio returns (for portfolio No. 2) for the given period taking into account the specified constraints is $40.18 \%$ to $696.48 \%$ (Table 8 ).

Contribution to the risk of each asset is given in table 9.

Figure 6 shows the effective frontier for assets NFLX, BA, PYPL, MSFT and BTC. The portfolios below it are ineffective. Respectively, it makes no sense to invest $100 \%$ of funds only in PYPL, BA or NFLX. The best ratio of risk and return is at the efficient frontier. Thus, effec- 
Table 11

Risk assessment results

\begin{tabular}{llcc}
\hline & \multicolumn{1}{c}{ Risks } & Likelihood & Risk level \\
\hline 1 & Security risks & Medium & High \\
2 & Technical risks (not considered) & & \\
3 & Economic risks associated with mining & Medium & High \\
4 & Risks associated with ICO & High & High \\
5 & Legal and regulatory risks & High & High \\
6 & Social risks /risks of acceptance & Medium & Medium \\
7 & Investment risks (volatility) & High & High \\
\hline
\end{tabular}

Source: author's calculations.

tive is the portfolio consisting only of bitcoins with an expected return of about $700 \%$ and a standard deviation of $120 \%$. Not every investor agrees with this asset allocation.

So, we cannot claim that a portfolio at the effective frontier is the best/optimal for an investor. To choose, it is necessary to know his preferences that are expressed in a risk and return ratio. It is generally described by the utility function.

On the graph, this function is represented by a number of curves, of each consists of points that have equal value and utility increases when the curves shift to the top-left. The most common is the quadratic (classical) utility function:

$$
U=r-\alpha^{*} \sigma^{2}
$$

where $\alpha$ is risk aversion coefficient.

The smaller the coefficient, the more investor is prone to risk: the less reward in units of expected return he requires. Then the utility function is flat (U 2). If an investor is not risktolerant, then the line goes up steeply (U 1). The simplest way to assess the investor's attitude to risk is by interviewing or analyzing his actual market behaviour.

Therefore, the optimal portfolio is at the tangency point of the utility curve and effective frontier. At this point, the angle of the effective frontier is equal to the tangent of the utility curve angle. Graphically, the risk aversion coefficient is the angle of the utility curve at the tangency point of its effective frontier.
In our case, only a very narrow group of investors can afford to invest $82 \%$ of funds in bitcoins and the remaining 18\% - in NFLX because then, the Expected Return will be 532\%, and Standard Deviation - 93\%.

Another approach is to modify crypto-portfolio with traditional financial assets. Then, the first stage is to identify cryptocurrencies with low correlation. Assuming that Bitcoin, as the most capitalized and popular cryptocurrency, will be the first asset in the portfolio, it is necessary to add altcoins with the lowest possible correlation. Over the past six months, it was Ethereum and Ripple (0.42 and 0.47 respectively). All other coins have a correlation with BTC above 0.7.

Obviously, having started investing money in 2017, a market participant would make a huge profit due to a jump in the cryptocurrency exchange rate in December 2017: the volatility risk would be levelled by investment return (105\% variance and end balance increased by 41 times). So, it makes sense to test crypto-portfolio from the beginning of the year to analyze diversification opportunities (Table 10). Rebalancing is not used.

It can be seen that a decrease in the cryptocurrency share from $100 \%$ to $30 \%$ in the portfolio significantly improved risk and return indicators. A conservative approach was about investing $10 \%$ in stock of a popular company Apple, 20\% - in the market leader by stock growth - Netflix, and 20\% each in traditional investment assets - oil and gold. Taking into account changes, it became possible to reduce 
the standard deviation from $75.5 \%$ to $4.3 \%$ making the return of the new portfolio positive.

The research on different portfolios has shown the following.

Monthly rebalancing is not always profitable, especially in a short term. But at the same time, this measure reduces the volatility of the portfolio.

It is necessary to consider the opportunity to quit cryptocurrency market for a short period of time to prevent harmful consequences of dramatic price shifts.

The portfolio should not be mostly "crypto" but rather it should consist of traditional assets, for example, gold, oil (Antonakakis et al., 2018), stocks or bonds in order to capture return from the growth (Uddin et al., 2018). Otherwise, it will remain a virtual profit. Plus, the presence of fiat assets gives an opportunity for a profitable purchase on corrections when the entire cryptocurrency market falls.

Thus, the diversification method has proved its worth and viability on empirical studies of portfolio investments. Probably, it is reasonable to split all the cryptocurrencies into segments and build a strategy based on this knowledge. For example:

Basic investments - Bitcoin, Ethereum, Litecoin, etc.

Platforms - Ethereum, NEO, Ark, etc.
Anonymous cryptocurrencies - Monero, Zcash, PivX, etc.

Banking/accounting solutions - Ripple, Stellar, etc.

Corporate solutions - VeChain, Walton, WABI, etc.

Innovative solutions - Raiblocks, IOTA, Cardano, etc.

Since the market is unstable at the current stage, most of the assets should be associated with "basic investments". Possible conditions for the formation of a high-return cryptocurrency portfolio may be thousand dollars of initial capital and priority for top-level coins.

In Table 11, the assessment of risks associated with cryptocurrencies is given.

Thus, it can be said that in view of novelty and innovativeness of the cryptocurrency market phenomenon, no $100 \%$ effective risk-management method exists. The only possible way is risk aversion - the refusal of any interaction with the cryptocurrency market. On the other hand, to reduce volatility risk, one of the most significant one that bothers investors all over the world, crypto-community should turn to traditional risk management methods of diversification that may acquire new opportunities. As cryptocurrencies are maturing and evolving into the significant asset class, we are going to witness in near future to what extent.

\section{References}

Antonakakis, N., Cunado, J., Filis, G., Gabauer, D., Gracia, F. P. (2018). Oil volatility, oil and gas firms and portfolio diversification. Energy Economics, 70, 499-515.

Anyfantaki, S., Arvanitis, S., Topaloglou, N. (2018). Diversification, Integration and Cryptocurrency Market. https://www.bankofgreece.gr/Pages/en/Publications/ConfPapers.aspx [accessed 31 Jan 2018].

Cocco, L., Marchesi, M. (2016). Modeling and Simulation of the Economics of Mining in the Bitcoin Market. PLOS ONE, 11(10), 1-42.

CoinDesk official site. https://www.coindesk.com [accessed 01 Feb 2018].

Corbet, S., Meegan, A., Larkin, C., Lucey, B., Yarovaya, L. (2018). Exploring the dynamic relationships between cryptocurrencies and other financial assets. Economics Letters, 165, 28-34.

Crunchbase official site. https://www.crunchbase.com [accessed 01 Feb 2018]

Hassani, B.K. (2016). Scenario Analysis in Risk Management: Theory and Practice in Finance. (1st ed.), Cham: Springer International Publishing.

Kanuri, S., Malhotra, D., Malm, J. (2018). Evaluating the Performance and Diversification Benefits of EmergingMarket Exchange-Traded Funds. The Journal of Wealth Management, 20(4), 85-90.

Kozina, E.V. (2017). Bitcoin as an attractive investment tool: opportunities and risks. Clusters in the Russian economy: essence, problems and development prospects, 55-58.

Token Sales \& ICOs List. https://www.coinschedule.com [accessed 01 Feb 2018]

Uddin, G. S., Hernandez, J. A., Shahzad, S. J., Hedström, A. (2018). Multivariate dependence and spillover effects across energy commodities and diversification potentials of carbon assets. Energy Economics, 71, 35-46. 
Анализ рисков криптовалют и способы их минимизации в современных рыночных условиях

\author{
Елена Надырова
}

Магистрантка 2 года обучения по программе «Международные финансы», Международный Финансовый факультет, Финансовый университет, Москва, Россия

ddasamm@mail.ru

Аннотация. В ходе исследования автором статьи были идентифицированы семь групп рисков, проанализировано их влияние, сформулированы возможные меры по снижению всех видов рисков. Для проектов первичных размещений криптоактивов сформулирована специальная система оценки рисков, основанная на 100-балльной шкале. Инвестиционный риск (волатильность) был одним из основных объектов исследования. Единственным эффективным вариантом управления данным видом риска является отказ от любого взаимодействия с криптовалютным рынком. С другой стороны, традиционный метод управления рисками - диверсификация портфельных инвестиций - доказал свою ценность и жизнеспособность. Портфель не должен ограничиваться только криптовалютой, а обязательно должен включать в себя и традиционные виды активов. Необходимо также рассматривать возможность выхода с криптовалютного рынка на некоторый период времени, чтобы иметь возможность предотвратить опасные последствия резких скачков цен.

Ключевые слова: криптовалюта; криптовалютный рынок; биткоин; риск-менеджмент; диверсификация; инвестиционный портфель; криптоактивы; оценка инвестиционных рисков JEL Classification: G02, G11, G29 